\title{
Short-term effects of regrouping on behavior of prepartum dairy cows
}

\author{
K. Schirmann, ${ }^{\star} \dagger$ N. Chapinal, ${ }^{\star}$ D. M. Weary, ${ }^{\star}$ W. Heuwieser, ${ }^{*} \dagger$ and M. A. G. von Keyserlingk ${ }^{* 1}$ \\ *Animal Welfare Program, Faculty of Land and Food Systems, The University of British Columbia, 2357 Main Mall, Vancouver, \\ BC, V6T 1Z4, Canada \\ †Clinic for Animal Reproduction, Faculty of Veterinary Medicine, Freie Universität Berlin, Königsweg 65, 14163 Berlin, Germany
}

\begin{abstract}
The objectives were to determine the effect of regrouping during the dry period on feeding, social, rumination, and lying behavior for cows that were moved to a new pen and cows that remained in their home pen but had new cows introduced. Forty-eight prepartum Holstein dairy cows were housed in groups of 6 and regrouped in groups of 3 (16 triads) with 1 triad moving to another pen and 1 triad staying in the same pen; the triad was considered the experimental unit. For $7 \mathrm{~d}$ before and 8 $\mathrm{d}$ after regrouping, cows were continuously monitored for feeding, rumination, and lying behavior by means of an electronic feeding system, a rumination logger on each cow's neck, and a data logger attached to 1 of the hind legs, respectively. Video recording was used to monitor displacements at the feeder for $3 \mathrm{~h}$ following the afternoon fresh feed delivery before regrouping and for the 2 subsequent afternoon feed deliveries after regrouping. Cows that were moved to a new pen after regrouping decreased DMI by approximately $9 \%$ on the day of regrouping compared with baseline values, but cows that remained in their home pen showed no significant decrease in intake after regrouping. Feeding rate decreased in both treatments by $10 \%$ after regrouping. Rumination times also decreased by approximately $9 \%$ in both treatments, reaching the lowest values on the day of regrouping for cows that stayed in the home pen and on the day after regrouping for the moved cows. Cows that were moved to a new pen displaced other cows at the feeder twice as frequently after regrouping, but no such effect of regrouping on cows that stayed in the home pen was observed. These results indicate that regrouping can affect behavior of prepartum dairy cows, especially those cows that are moved to a new pen.
\end{abstract}

Key words: regrouping, dry period, behavior, rumination

Received July 21, 2010.

Accepted January 17, 2011.

${ }^{1}$ Corresponding author: marina.vonkeyserlingk@ubc.ca

\section{INTRODUCTION}

In modern dairy production systems, regrouping of cows is a common management practice, and many cows experience 4 or more regroupings per lactation. As regrouping strategies are usually based on stage of lactation, reproductive status, and dietary requirements, the majority of regrouping events take place immediately before, during, and immediately after the dry period (Cook and Nordlund, 2004). For example, at the end of lactation the cow may be regrouped to facilitate dryoff. After dry-off, cows are often regrouped into a far-off group, followed by another regrouping into a close-up group at approximately $21 \mathrm{~d}$ before calving. Cows are again moved and often regrouped in a maternity pen in the days immediately before parturition, and moved again to a fresh pen immediately after calving when the cow enters the lactating herd (Smith et al., 2001). Each regrouping exposes the cow to new individuals or new combinations of individuals, hence a changing group composition, contributing to social turmoil (Cook and Nordlund, 2004; von Keyserlingk et al., 2008).

When lactating cows are regrouped they re-establish social relationships using non-physical and physical interactions (Arave and Albright, 1976; Kondo and Hurnik, 1990). Earlier work has shown that regrouping can have negative consequences on both milk production (Arave and Albright, 1976; Hasegawa et al., 1997) and behavior, such as an increase in agonistic interactions (Brakel and Leis, 1976) or a decrease in feeding time (Hasegawa et al., 1997). von Keyserlingk et al. (2008) monitored cows in midlactation before and after they were placed into a new social group. Their results show that after regrouping, the animals decreased time spent feeding, time spent lying down, and time spent engaged in allogrooming compared with before regrouping.

Previous work has shown that the number of aggressive interactions is most frequent immediately after regrouping (Brakel and Leis, 1976; Kondo and Hurnik, 1990; von Keyserlingk et al., 2008), with regrouped cows being displaced more often from the feeding area by other cows. Much of the social competition in a group pen occurs in the feeding area (Val-Laillet et al., 2008) and this competition can lead to a dramatic decrease 
in time spent feeding, particularly for subordinate cows (DeVries et al., 2004; Huzzey et al. 2006).

Changes in feeding time and DMI likely affect rumination behavior (Okine and Mathison, 1991), and factors that directly affect rumination may affect feeding behavior and DMI. For instance, steers that were prevented from ruminating by wearing a tight mask, preferred to ruminate instead of eat fresh hay when the mask was removed (Welch, 1982). Moreover, it has long been accepted that rumination is necessary for particle breakdown and microbiological digestion required for passage through the digestive tract (Balch, 1952). Hence, one would assume that preventing a ruminant from ruminating and emptying the rumen would cause a decrease in voluntary feed intake.

Social stress in cattle can be linked to a decrease in time spent ruminating (Bristow and Holmes, 2007). Yet, only one study (Hasegawa et al., 1997) has examined the effects of regrouping on rumination behavior in loose-housed cattle, but this work studied heifers and did not start to monitor rumination until $2 \mathrm{~d}$ after regrouping.

Although some studies show evidence suggesting that regrouping events are associated with changes in behavior for animals relocated to a new pen (Lamb, 1976; Arave and Albright, 1976), to date, no study has examined the effects of regrouping on cows already in the pen. Moreover, little work has been done to investigate the effect of regrouping on dairy cows during the dry period.

The objectives were to determine the effect of regrouping cows during the dry period on DMI, feeding behavior, rumination behavior, and lying behavior for a) cows that were moved to a new group in a different pen and b) cows that were in a pen in which new cows were introduced. Given the results of previous work we hypothesized that regrouping far-off dairy cows would result in decreased feeding time, DMI, lying time, and time spent ruminating, and increased feeding rate and aggressive behavior at the feed bunk. We also hypothesized that these effects of regrouping would be greater for cows moved to a new pen than for cows kept in their home pen.

\section{MATERIALS AND METHODS}

\section{Animals, Housing, and Diet}

A total of 48 multiparous nonlactating Holstein dairy cows (parity $=2.2 \pm 1.4$; mean $\pm \mathrm{SD}$ ) were observed. The cows were enrolled at $40 \pm 8 \mathrm{~d}$ before their expected calving date and had been not lactating $21 \pm 10$ d. The study was conducted between November 2008 and January 2009 at the University of British Colum- bia's Dairy Education and Research Centre (Agassiz, BC, Canada). Animals were cared for according to the guidelines set by the Canadian Council on Animal Care (1993).

Two experimental pens, housing 6 cows each, were used. The pens were separated by a non-experimental pen that housed 12 cows, ensuring no direct social contact between cows housed in the 2 pens. All pens were located in 1 row on the same side in 1 barn and had the same measurements of $10.2 \times 13 \mathrm{~m}$. Each pen was equipped with 6 Insentec feed bins, 1 Insentec water bin (Insentec, Marknesse, the Netherlands), and 12 stalls (for stall dimensions see Reich et al., 2010) in 2 rows of 6 , fitted with a mattress (Pasture Mat, Promat Inc., Woodstock, Ontario, Canada) covered with approximately $5 \mathrm{~cm}$ of washed river sand. Cows were provided access to only 3 of the 6 feed bins, resulting in a cow-to-feed bin ratio of 2:1. The Insentec system was programmed to allow all cows to access all 3 feed bins and the water bin. Cows were allowed access to 1 of the 2 rows of stalls with the other row being blocked, resulting in a cow-to-stall ratio of 1:1.

The cows were fed a TMR formulated according to the recommendations provided by the National Research Council (NRC, 2001). Cows were fed with ad libitum intake and fresh feed was provided twice daily at approximately $0800 \pm 1 \mathrm{~h}$ and $1600 \pm 1 \mathrm{~h}$. Feed samples were collected twice weekly, at the time of fresh feed delivery, from both pens and then pooled. The samples were stored in a freezer and then thawed and dried at $60^{\circ} \mathrm{C}$ for $2 \mathrm{~d}$ to determine the DM content. For nutrient analysis, the dried samples were sent to Cumberland Valley Analytical Services, Inc. (Maugansville, MD) to determine the average $( \pm \mathrm{SD}) \mathrm{CP}, \mathrm{ADF}, \mathrm{NDF}$, total digestible nutrients, and $\mathrm{NE}_{\mathrm{L}}$ content of the feed fed throughout the study. The TMR consisted of $43.6 \%$ grass silage, $39.7 \%$ corn silage, $12.7 \%$ straw, and $4.0 \%$ mineral and concentrate mix on a DM basis (DM: 95.05 $\pm 0.25 \%$; CP: $15.1 \pm 1.4 \%$ of DM; ADF: $32.2 \pm 3.3 \%$ of DM; NDF: $53.05 \pm 4.55 \%$ of DM; and $\mathrm{NE}_{\mathrm{L}}: 1.43 \pm$ $0.7 \mathrm{Mcal} / \mathrm{kg})$.

\section{Experimental Design}

A total of 48 cows (parity $=2.2 \pm 1.4$ ) was used, divided into 4 replicates of 12 cows. For each replicate, 12 nonlactating cows were randomly selected, without replacement, using a random number generator (Excel, version 2003; Microsoft, Redmond, WA) and divided into 2 groups of 6 cows. Each group of 6 was housed in 1 of 2 experimental pens. Groups were allowed to stabilize for $3 \mathrm{~d}$ and then baseline recordings for feeding, rumination, and lying behaviors were taken for 7 consecutive days before regrouping ( $\mathrm{d}-7$ to -1 ). Regroup- 
ing took place on d 0 , at which time 3 cows from each group (referred to as a triad) were randomly selected and moved to the other experimental pen. Hence, each group provided 2 triads, of which 1 triad remained in the pen and was mixed with a triad from the other pen; following regrouping, each experimental pen once again contained 6 cows. The regrouping always took place between 1200 and $1300 \mathrm{~h}$ and was undertaken by the same 3 individuals. All cows were moved to a sorting pen, divided into triads, and then returned to the appropriate pens. Feeding, rumination, and lying behaviors were recorded following regrouping beginning at $1300 \mathrm{~h}$ on $\mathrm{d} 0$ for 8 consecutive days.

\section{Behavioral Recording}

Feeding Behavior. The Insentec system, previously validated by Chapinal et al. (2007), was used to record individual feed intake and time spent feeding. The Insentec system records the cow identification, time, duration, and amount of feed consumed during every visit to a feed bin. As fed intakes were corrected for DM content, the results are reported as DMI per visit. The DMI per visit and feeding time were used to calculate feeding rate per visit.

Social Behavior. To observe social interactions while feeding, each pen was equipped with 1 camera connected to a digital video recording system (Genetec Inc., Saint-Laurent, Quebec, Canada). The camera (WV-BP330, Panasonic, Osaka, Japan) was mounted $6 \mathrm{~m}$ above the feed bins. Social behavior was recorded for $3 \mathrm{~h}$ after the afternoon feed delivery on $\mathrm{d}-1,0$, and 1 relative to regrouping. An interaction between 2 cows was considered a displacement from the feed bin when physical contact initiated by 1 cow (actor) caused the receiving cow (reactor) to stop feeding, back out and entirely remove her head from the feed bin so that the drop-down gate to the bin closed. A replacement was recorded if the actor immediately placed her head in the same feed bin. Inter-observer reliability between 2 trained observers, and intra-observer reliability, to ensure that no changes over time occurred in analyzing the videos, resulted in robust agreement $\left(\mathrm{R}^{2}>0.95\right)$. Inter- and intra-observer reliability were calculated using the REG procedure for linear regression in SAS.

Rumination Behavior. Ten days before regrouping, all cows were fitted with individual rumination loggers (HR-Tag, SCR, Netanya, Israel) to record rumination time. The rumination logger continuously records the duration of rumination in 2-h intervals, as validated by Schirmann et al. (2009). For data transfer, automatic readers, purchased from the same company as the loggers, were located above the water bins.
Lying Behavior. Ten days before regrouping, all cows were fitted with activity loggers (HOBO Pendant G, Onset, Cape Cod, MA), attached to 1 hind leg and programmed to record the position of the cow (lying or standing; standing still and walking are both registered as standing in an upright position) in 1-min intervals (Ledgerwood et al., 2010). These measurements were used to calculate the frequency of lying bouts, their duration, and the total daily lying time.

\section{Data Analysis}

Statistical analyses were performed with SAS (version 9.1, SAS Institute, 2003; SAS Institute Inc., Cary, $\mathrm{NC}$ ) considering the triad (i.e., the 3 cows moved or the 3 cows that remained) as the experimental unit $(\mathrm{n}=16$ triads). Two of the animals calved during the course of the experiment and were removed, resulting in the exclusion of 2 triads from all analysis. Three other triads were excluded from the analysis of displacements and replacements due to technical problems with the video recording system.

Feeding events were screened for the presence of outliers based on feeding rate, as described by Huzzey et al. (2007). Behavioral data were summarized to calculate cow averages per triad and day. Feeding, rumination, and lying behavior data recorded during $\mathrm{d}-7$ and -6 before regrouping were averaged to give 1 baseline value for each triad. These days were chosen as 1 animal calved in 1 of the observation pens overnight on $\mathrm{d}$ -5 , which affected the behavior of the other animals in that pen, and a problem with the feeding equipment occurred on $\mathrm{d}-2$ in 1 of the replicates. Due to technical restrictions, $\mathrm{d}-1$ was used as a baseline for social behavior. All data were initially analyzed using a mixed model (PROC MIXED) that included triad as a random effect, replicate as a block, treatment (i.e., the triad remained in the same pen or was moved to a new pen) as a fixed effect, time period relative to regrouping as a repeated measure, and the interaction between treatment and time period. Preliminary analysis revealed an interaction between treatment and period, so our further analysis tested the effect of period separately for the 2 treatments. Contrast statements were used to test the baseline period against each of the $3 \mathrm{~d}$ following regrouping (d 0, 1, and 2) within each treatment for all variables. The analysis was limited to these days based on preliminary analysis showing that response to regrouping was clearest on the days immediately following regrouping. Residuals were plotted and visually examined to assess normality and homogeneity of variances. All values reported are least squares means \pm standard error. Significance was declared at $P \leq 0.05$. 
Table 1. Least squares means $( \pm \mathrm{SE})$ for DMI, feeding time, feeding rate, and number of visits to the feed bin before (baseline) and after regrouping ( $\mathrm{d} 0$ to 2 ) for dry Holstein dairy cows ( $\mathrm{n}=14$ triads) that remained in the same pen or that were moved to a new pen ${ }^{1}$

\begin{tabular}{|c|c|c|c|c|}
\hline \multirow[b]{2}{*}{ Variable } & \multicolumn{4}{|c|}{ Time period relative to regrouping } \\
\hline & Baseline $^{2}$ & d 0 & d 1 & d 2 \\
\hline \multicolumn{5}{|l|}{ DMI (kg/d) } \\
\hline Remained & $13.8 \pm 0.4$ & $13.5 \pm 0.4$ & $13.3 \pm 0.4$ & $12.9 \pm 0.4$ \\
\hline Moved & $14.5 \pm 0.4$ & $13.2 \pm 0.4^{*}$ & $13.8 \pm 0.4$ & $14.4 \pm 0.4$ \\
\hline \multicolumn{5}{|c|}{ Feeding time $(\min / \mathrm{d})$} \\
\hline Remained & $246.0 \pm 9.1$ & $259.1 \pm 9.1$ & $258.9 \pm 9.1$ & $255.1 \pm 9.1$ \\
\hline Moved & $250.4 \pm 11.1$ & $238.5 \pm 11.1$ & $249.2 \pm 11.1$ & $269.6 \pm 11.1$ \\
\hline \multicolumn{5}{|c|}{ Feeding rate $(\mathrm{g} / \mathrm{min})$} \\
\hline Remained & $64.5 \pm 2.1$ & $57.5 \pm 2.1^{*}$ & $57.3 \pm 2.1^{* *}$ & $57.0 \pm 2.1^{* *}$ \\
\hline Moved & $62.9 \pm 2.1$ & $57.6 \pm 2.1^{* *}$ & $60.0 \pm 2.1$ & $57.3 \pm 2.1^{* *}$ \\
\hline \multicolumn{5}{|l|}{ Visits (n/d) } \\
\hline Remained & $48.7 \pm 3.0$ & $50.2 \pm 3.0$ & $52.5 \pm 3.0$ & $47.0 \pm 3.0$ \\
\hline Moved & $47.4 \pm 3.8$ & $49.2 \pm 3.8$ & $50.1 \pm 3.8$ & $50.9 \pm 3.8$ \\
\hline
\end{tabular}

\section{RESULTS}

\section{Feeding Behavior}

Cows that were moved to a new pen after regrouping decreased DMI by approximately $9 \%$ on d 0 compared with the baseline period before regrouping, whereas cows that remained in the home pen did not change DMI (Table 1). Both treatments showed significantly decreased feeding rates on the day of regrouping relative to the baseline period, and this decrease persisted until d 2 for animals that remained in the home pen. Feeding rates for cows that were moved to a new pen returned to baseline on d 1 but decreased again on d 2 . No effect of regrouping on the number of visits to the feed bin or the daily feeding time was observed in either of the 2 treatments.

\section{Social Behavior}

Cows that were moved to a new pen showed a gradual increase in number of displacements initiated (as an actor) at the feeder in the $3 \mathrm{~h}$ following the afternoon fresh feed delivery, resulting in twice as many displacements on the day after regrouping than on the day before $(12.0 \pm 1.5$ vs. $5.7 \pm 1.5$ displacements $/ 3 \mathrm{~h}$ for d 1 and baseline, respectively; Figure $1 \mathrm{~A}$ ). But, this was the only significant change, as these animals did not show any changes in the number of displacements received or in the number of replacements initiated or received (Figure 1B - D). No changes were observed in social behavior at the feed bunk for cows that remained in their home pen.

\section{Rumination Behavior}

Cows that remained in the same pen significantly decreased the time spent ruminating on d 0 (498.6 \pm 11.0 vs. $530.7 \pm 11.0 \mathrm{~min} / \mathrm{d}$ for $\mathrm{d} 0$ and baseline, respectively), but returned to baseline values on the day following regrouping (Figure 2). But, cows that were moved to a new pen had a significant decrease in rumination times on the day after regrouping (481.5 \pm 18.9 vs. $510.6 \pm 18.9 \mathrm{~min} / \mathrm{d}$ for $\mathrm{d} 1$ and baseline, respectively), returning to baseline values on $\mathrm{d} 2$.

\section{Lying Behavior}

Cows that were moved to a new pen showed a modest, yet significant increase in the number of lying bouts on $\mathrm{d} 0$ and 1 (baseline: $7.2 \pm 0.5$ bouts/d; d 0: $8.2 \pm$ $0.5 ; \mathrm{d} 1: 8.3 \pm 0.5$; Figure $3 \mathrm{~A}$ ). No changes in number of lying bouts occurred for cows that remained in the same pen. No changes were observed in daily lying time after regrouping in either treatment (Figure $3 \mathrm{~B}$ ).

\section{DISCUSSION}

The results illustrate the short-term effects of regrouping on the behavior of dairy cows during the dry period. To our knowledge, this is the first study to demonstrate that, when compared with premixing, the behavioral response of cows regrouped by moving them to a new group is different than the response of cows that remain in their home pen.

The average daily DMI supported previous reports for nonlactating cows by Andersen et al. (2005) and 
A)

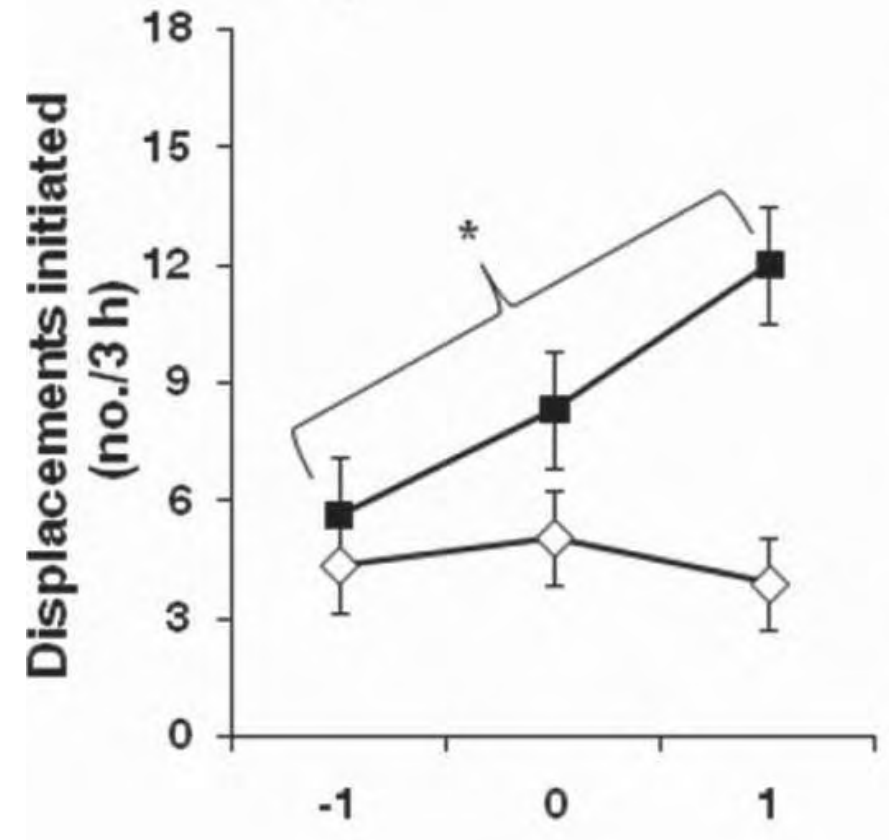

C)

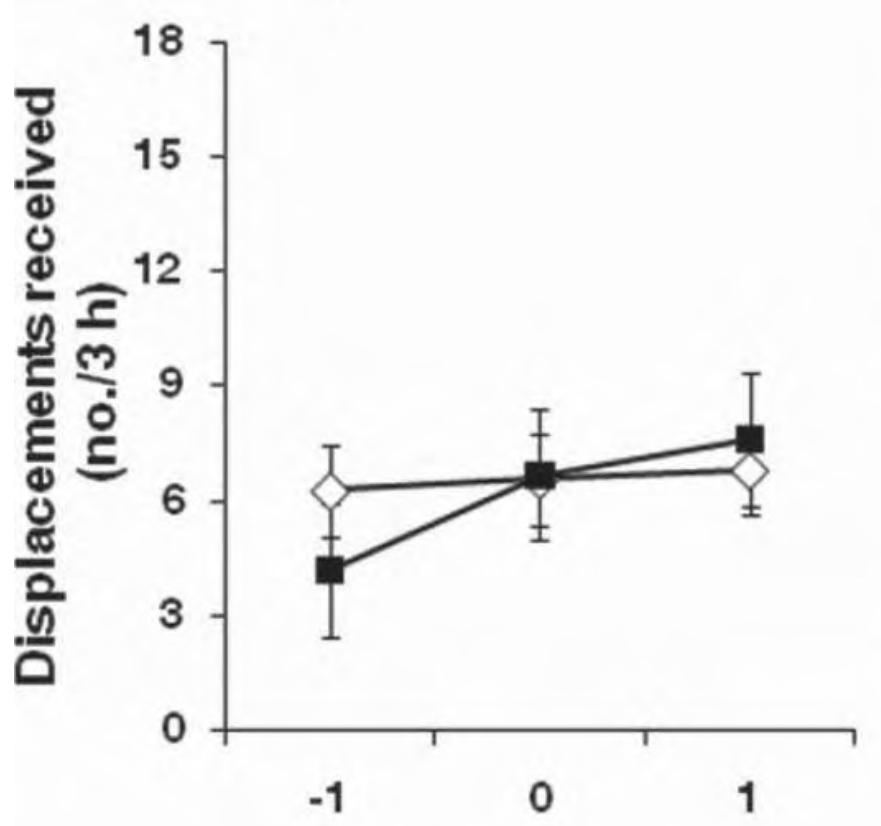

B)

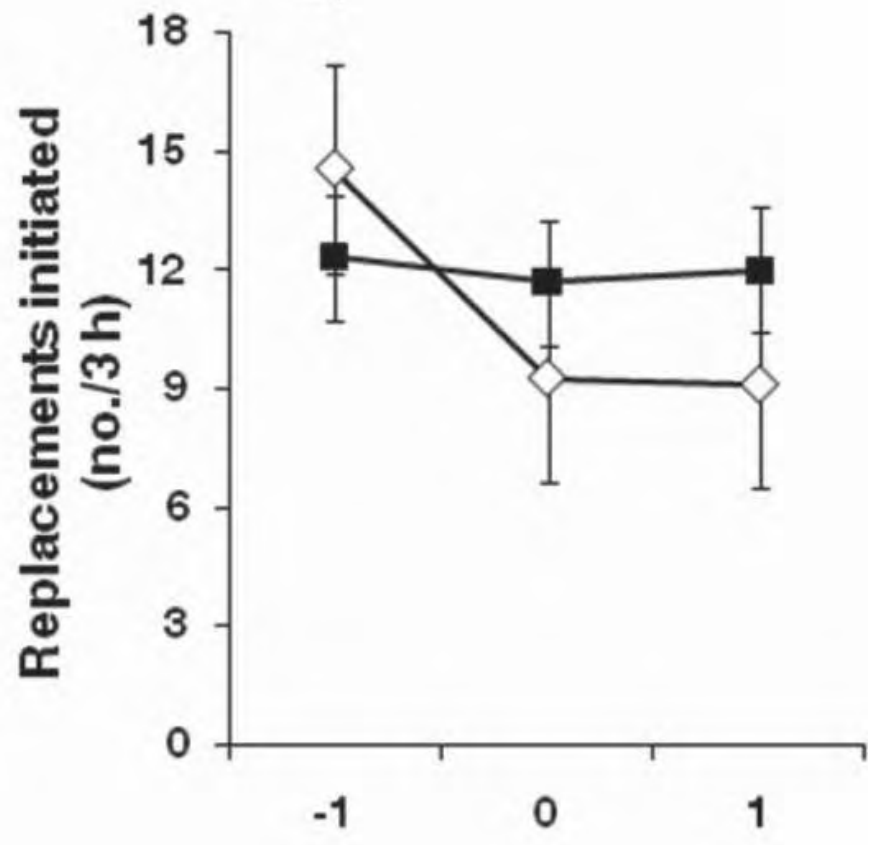

D)

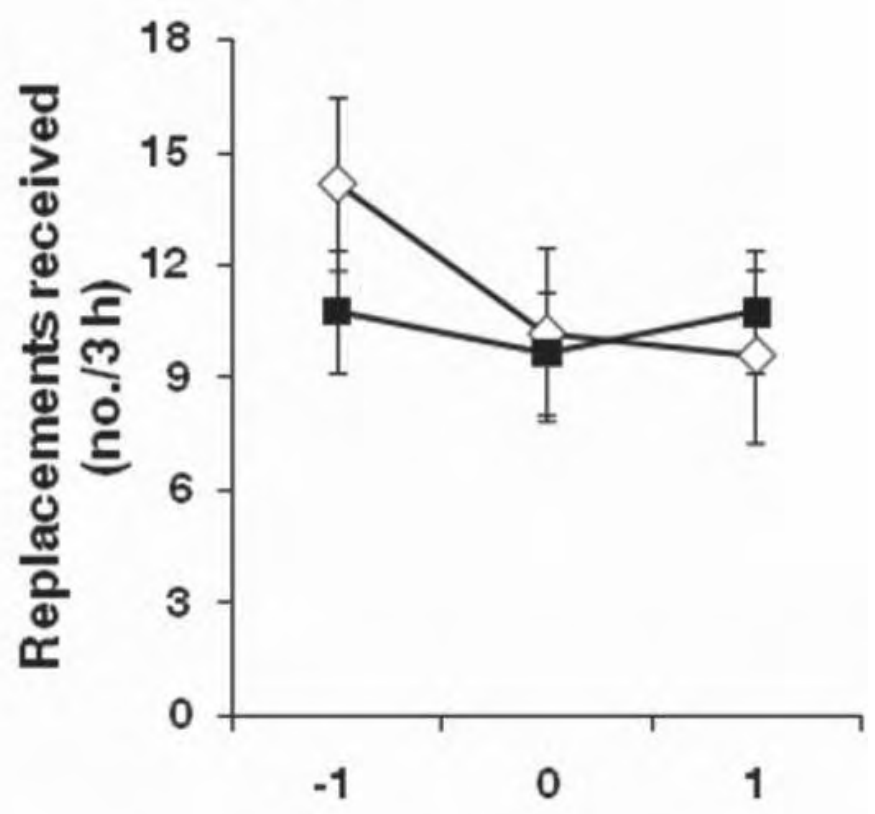

\section{Time period relative to regrouping (d)}

Figure 1. Number of competitive displacements initiated (A), replacements initiated (B), displacements received (C), and replacements received (D) per cow during the $3 \mathrm{~h}$ following the fresh feed delivery in the afternoon on $\mathrm{d}-1,0$, and 1 relative to regrouping for nonlactating Holstein dairy cows that remained in the same pen $(\mathrm{n}=6$ triads; $\diamond)$ or that were moved to a new pen $(\mathrm{n}=5$ triads; $\mathbf{\square})$. Cows were regrouped before the start of $\mathrm{d} 0$ between 1200 and $1300 \mathrm{~h}$ and feed was delivered at $1600 \mathrm{~h}$. Asterisk indicates $P<0.05$ for displacements initiated (A) when $\mathrm{d}-1$ was tested against $\mathrm{d} 1$, for cows that were moved to a new pen. 


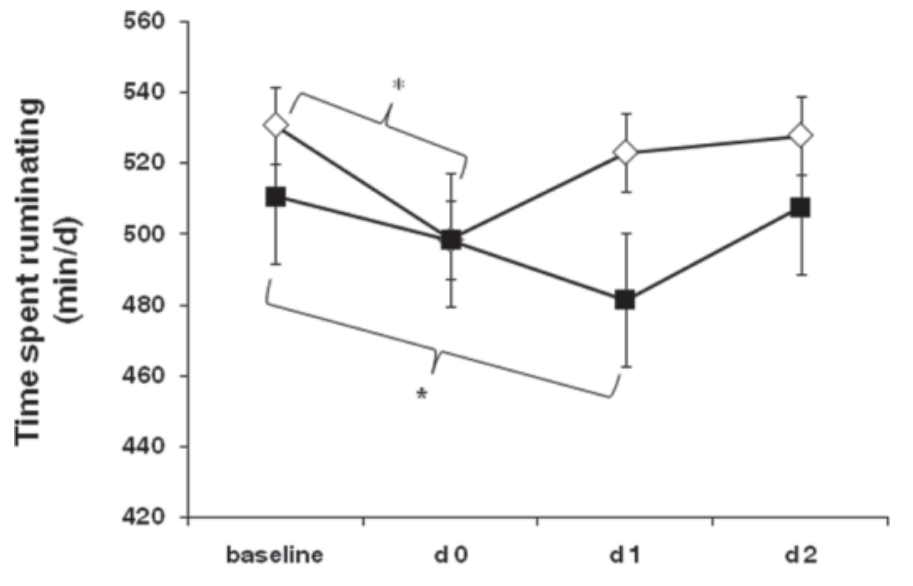

Time period relative to regrouping

Figure 2. Time spent ruminating ( $\mathrm{min} / \mathrm{d}$ ) before (baseline) and after regrouping ( $\mathrm{d} 0$ to 2 ) for nonlactating Holstein dairy cows that remained in the same pen $(\mathrm{n}=7$ triads; $\diamond)$ or that were moved to a new pen ( $\mathrm{n}=7$ triads; $)$. Cows were regrouped before the start of $\mathrm{d}$ 0 between 1200 and $1300 \mathrm{~h}$ and feed was delivered at $1600 \mathrm{~h}$. Upper asterisk indicates $P<0.05$ when baseline (mean of $\mathrm{d}-7,-6$ ) was tested against $\mathrm{d} 0$ for cows that remained in the pen; lower asterisk indicates $P<0.05$ when baseline (mean of $\mathrm{d}-7,-6$ ) was tested against $\mathrm{d} 1$ for cows that were moved to a new pen.

Silva-del Río et al. (2010). Cows that were moved to a new pen decreased DMI only on the day of regrouping, but cows that remained in the home pen did not show any changes. We suggest that this short-term decrease in DMI for cows that were moved to a new pen is a consequence of the combined stressors of a new physical and social environment; cows that remained in their home pen were only required to cope with the new social partners and, thus, were not affected to the same extent. Stricklin et al. (1980) reported a home-pen advantage when they examined the effect of regrouping on social hierarchy in beef steers. After regrouping, dairy cows must establish their position in the new hierarchy of the new group. It can be assumed that regrouping likely is a stressful event (Lamb, 1976). Moreover, the effects of combining stressors and uncoupling them have been shown in other contexts. For example, Haley et al. (2005) showed an increased distress response in beef calves weaned from their mother, and thus, no longer able to nurse, compared with a 2 -step method when the calves were first prevented from suckling the dam and then separated from their dam 3 d later.

Similar to data reported by von Keyserlingk et al. (2008), the present results show that daily time spent feeding did not change after regrouping. Yet, they found a decrease in feeding time during the first hour after feed delivery in the morning, directly after milking and regrouping. In the current study, feeding times varied across days and feed delivery took place approximately
$3 \mathrm{~h}$ after regrouping, preventing a similar analysis. Feeding rate decreased after regrouping both for cows that were moved and cows that remained. Most previous work has found increased feeding rate in response to increased competition (Olofsson, 1999; Hosseinkhani et al. 2008; Proudfoot et al. 2009). The decreased feeding rate in the present study may be explained by an increase in vigilance behavior after regrouping, because competition at the feed bin was kept constant with a cow-to-feed bin ratio of 1:2. Studies on birds have shown decreased feeding rates in response to increased vigilance behavior following changes in group size (Beauchamp, 1998). Welp et al. (2004) studied vigilance as a measure of fear in dairy cattle and concluded that vigilance in dairy cows can be measured as a trade-off between feeding and vigilant behaviors; in other words, vigilance behaviors can influence the feeding behavior, especially considering that these authors reported that the level of vigilance displayed by dairy cows increased depending on the external threat. The feed bins used in the current study restricted the visual field of the feeding animals, such that the cows may have interrupted feeding bouts to scan for potential threats, including pen mates. It is likely that socially subordinate animals were most affected, but the design of this study (with treatment applied to triad rather than individual) precluded any meaningful analysis of social status. We suggest that future research take into consideration the effects of social rank, assessing the effect of regrouping on dominant, middle-ranked, and subordinate cows.

Contrary to previous work (von Keyserlingk et al., 2008), only minor changes were observed in social behavior at the feed bin after regrouping. These authors found that single cows introduced into a pen with a stable group of 11 other animals experienced increased displacements for up to $3 \mathrm{~d}$ following regrouping. Brakel and Leis (1976) reported that cows introduced to a new pen were involved in almost twice as many agonistic encounters compared with cows that were already in the pen on the day of regrouping. The increased number of social interactions at the feed bin may be explained by the increased motivation to feed immediately after fresh feed delivery (DeVries et al., 2003), which in the previous studies coincided with the time of regrouping. In the present study, cows were regrouped in the middle of the day and $3 \mathrm{~h}$ before feeding. von Keyserlingk et al. (2008) introduced a single focal cow to the new group, but in the current study, 3 cows that had been previously housed together were introduced. These results indicate that regrouping cows in groups, and avoiding peak feeding times, can decrease the frequency of aggressive interactions after regrouping.

To the best of our knowledge, the results of the current study are the first to show a decrease in time spent 

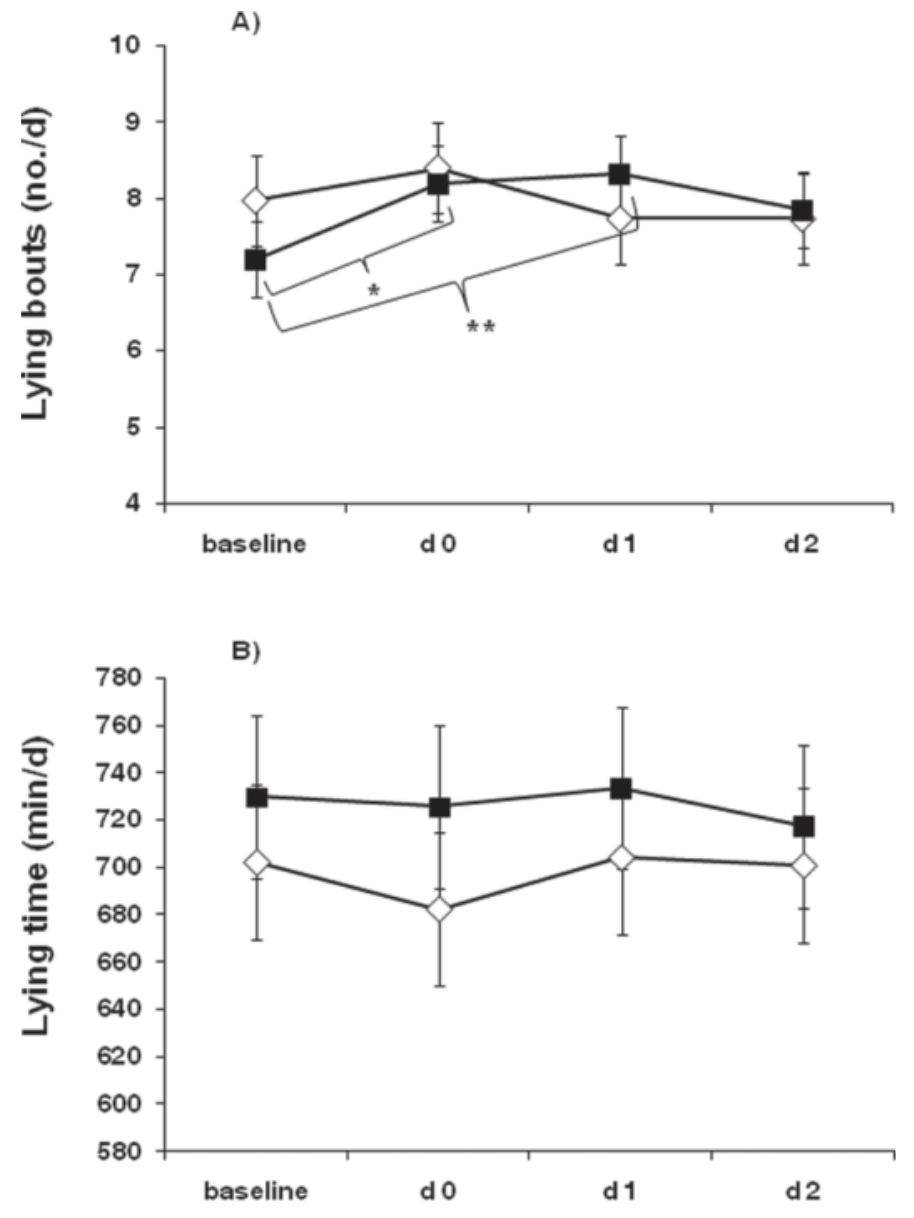

Time period relative to regrouping

Figure 3. Number of lying bouts (no./d; A) and lying time (min/d; B) before (baseline) and after regrouping (d 0 to 2 ) for Holstein dairy cows that remained in the same pen $(\mathrm{n}=7$ triads; $\diamond)$ or that were moved to a new pen $(\mathrm{n}=7$ triads; $\mathbf{\square})$. Single asterisk indicates $P<$ 0.05 for lying bouts when baseline (mean of $\mathrm{d}-7,-6$ ) was tested against d 0 and double asterisks indicate $P<0.01$ when baseline (mean of $\mathrm{d}-7,-6$ ) was tested against $\mathrm{d} 1$ for cows that were moved to a new pen.

ruminating after regrouping in loose-housed dairy cows. Cows that remained in the pen and had new animals introduced showed a decrease in time spent ruminating only on the day of regrouping; cows moved to a new pen also showed a decrease in rumination behavior on the day after regrouping, likely due to decreased DMI on d 0. Hasegawa et al. (1997) reported no difference in time spent ruminating following regrouping in dairy heifers, but observations began $2 \mathrm{~d}$ after regrouping; the results of the current study suggest that animals will return to baseline after $2 \mathrm{~d}$. We, therefore, speculate that in the present study, the decreased ruminating times may have been due to the distress of regrouping, with the greatest effects on those animals that were both moved and regrouped.
Unlike previous work (von Keyserlingk et al., 2008), no difference in lying time after regrouping was observed. A change in the number of lying bouts occurred, which increased for cows moved to a new pen on the days immediately following regrouping. This result may indicate some degree of restlessness in these animals, but future work is required to confirm this.

In conclusion, regrouping can affect behavior of prepartum dairy cows. These effects are greatest for cows that moved to a new pen at the time of regrouping. Behaviors such as daily rumination time may be useful variables to assess the short-term response to regrouping. As previously reported by von Keyserlingk et al. (2008), monitoring behavior before and after regrouping, and assessing the change were sensitive measures to assess the response of cows to regrouping. The interpretation of the results, that is, the direction and degree of change deemed detrimental for the animal health and welfare, will depend on the behavior itself as well as other cow- and group-level variables.

\section{ACKNOWLEDGMENTS}

We thank the staff of The University of British Columbia Dairy Education and Research Centre (Vancouver) and the University's Animal Welfare Program. In particular, we thank Doug Veira (Agriculture and AgriFood Canada), Lindsay Collings and Lori Vickers (University of British Columbia Animal Welfare Program) for their support. Kathrin Schirmann was funded by a scholarship from Tiergyn Berlin e.V. (Berlin, Germany). This research is supported by Canada's Natural Sciences and Engineering Research Council Industrial Research Chair Program with industry contributions from the Dairy Farmers of Canada (Ottawa, ON), Westgen (Milner, BC), Pfizer Animal Health (Kirkland, QC), BC Cattle Industry Development Fund (Kamloops, BC), the BC Milk Producers (Burnaby, BC), BC Dairy Foundation (Burnaby, BC), BC Dairy Education and Research Association (Vancouver, BC), and Alberta Milk (Edmonton, AB).

\section{REFERENCES}

Andersen, J. B., T. G. Madsen, T. Larsen, K. L. Ingvartsen, and M. O. Nielsen. 2005. The effects of dry period versus continuous lactation on metabolic status and performance in periparturient cows. J. Dairy Sci. 88:3530-3541.

Arave, C. W., and J. L. Albright. 1976. Social rank and physiological traits of dairy cows as influenced by changing group membership. J. Dairy Sci. 59:974-981.

Balch, C. C. 1952. Factors affecting the utilization of food by dairy cows. Br. J. Nutr. 6:366-375.

Beauchamp, G. 1998. The effect of group size on mean food intake rate in birds. Biol. Rev. Camb. Philos. Soc. 73:449-472.

Brakel, W. J., and R. A. Leis. 1976. Impact of social disorganization on behavior, milk yield, and body weight of dairy cows. J. Dairy Sci. 59:716-721. 
Bristow, D. J., and D. S. Holmes. 2007. Cortisol levels and anxietyrelated behaviors in cattle. Physiol. Behav. 90:626-628.

Canadian Council on Animal Care. 1993. Guide to the Care and Use of Experimental Animals. Vol.1. E. D. Olfert, B. M. Cross, and A. A. McWilliam, ed. CCAC, Ottawa, Ontario, Canada.

Chapinal, N., D. M. Veira, D. M. Weary, and M. A. G. von Keyserlingk. 2007. Technical note: Validation of a system for monitoring individual feeding and drinking behavior and intake in grouphoused dairy cattle. J. Dairy Sci. 90:5732-5736.

Cook, N. B., and K. V. Nordlund. 2004. Behavioral needs of the transition cow and considerations for special needs facility design. Vet. Clin. North Am. Food Anim. Pract. 20:495-520.

DeVries, T. J., M. A. G. von Keyserlingk, and K. A. Beauchemin. 2003. Short communication: Diurnal feeding pattern of lactating dairy cows. J. Dairy Sci. 86:4079-4082.

DeVries, T. J., M. A. G. von Keyserlingk, and D. M. Weary. 2004. Effect of feeding space on the inter-cow distance, aggression, and feeding behavior of free-stall housed lactating dairy cows. J. Dairy Sci. 87:1432-1438.

Haley, D. B., D. W. Bailey, and J. M. Stookey. 2005. The effects of weaning beef calves in two stages on their behavior and growth rate. J. Anim. Sci. 83:2205-2214.

Hasegawa, N., A. Nishiwaki, K. Sugawara, and I. Ito. 1997. The effects of social exchange between two groups of lactating primiparous heifers on milk production, dominance order, behavior and adrenocortical response. Appl. Anim. Behav. Sci. 51:15-27.

Hosseinkhani, A., T. J. DeVries, K. L. Proudfoot, R. Valizadeh, D. M. Veira, and M. A. G. von Keyserlingk. 2008. The effects of feed bunk competition on the feed sorting behavior of close-up dry cows. J. Dairy Sci. 91:1115-1121.

Huzzey, J. M., T. J. DeVries, P. Valois, and M. A. G. von Keyserlingk. 2006. Stocking density and feed barrier design affect the feeding and social behavior of dairy cattle. J. Dairy Sci. 89:126-133.

Huzzey, J. M., D. M. Veira, D. M. Weary, and M. A. G. von Keyserlingk. 2007. Prepartum behavior and dry matter intake identify dairy cows at risk for metritis. J. Dairy Sci. 90:3220-3233.

Kondo, S., and J. F. Hurnik. 1990. Stabilization of social hierarchy in dairy cows. Appl. Anim. Behav. Sci. 27:287-297.

Lamb, R. C. 1976. Relationship between cow behavior patterns and management systems to reduce stress. J. Dairy Sci. 59:16301636.

Ledgerwood, D. N., C. Winckler, and C. B. Tucker. 2010. Evaluation of data loggers, sampling intervals, and editing techniques for measuring lying behavior of dairy cattle. J. Dairy Sci. 93:5129-5139.

National Research Council (NRC). 2001. Nutrient Requirements of Dairy Cattle. 7th rev. ed. National Academy Press, Washington, DC.
Okine, E. K., and G. W. Mathison. 1991. Effects of feed intake on particle distribution, passage of digesta, and extent of digestion in the gastrointestinal tract of cattle. J. Anim. Sci. 69:3435-3445.

Olofsson, J. 1999. Competition for total mixed diets fed for ad libitum intake using one or four cows per feeding station. J. Dairy Sci. 82:69-79.

Proudfoot, K. L., D. M. Veira, D. M. Weary, and M. A. G. von Keyserlingk. 2009. Competition at the feed bunk changes the feeding, standing, and social behavior of transition dairy cows. J. Dairy Sci. 92:3116-3123.

Reich, L. J., D. M. Weary, D. M. Veira, and M. A. G. von Keyserlingk. 2010. Effects of sawdust bedding dry matter on lying behavior of dairy cows: A dose-dependent response. J. Dairy Sci. 93:1561-1565.

SAS Institute. 2003. SAS User's Guide. Version 9.1. SAS Institute Inc., Cary, NC.

Schirmann, K., M. A. G. von Keyserlingk, D. M. Weary, D. M. Veira, and W. Heuwieser. 2009. Technical note: Validation of a system for monitoring rumination in dairy cows. J. Dairy Sci. 92:60526055 .

Silva-del-Río, N., P. M Fricke, and R. R. Grummer. 2010. Effects of twin pregnancy and dry period feeding strategy on milk production, energy balance, and metabolic profiles in dairy cows. J. Anim. Sci. 88:1048-1060.

Smith, J. F., J. P. Harner III, and M. J. Brouk. 2001. Special needs facilities. Recommendations for housing pregnant, lactating and sick cows. Kansas State University Agricultural Experimental Station and Cooperative Extension Service EP100, Manhattan, KS.

Stricklin, W. R., H. B. Graves, L. L. Wilson, and R. K. Singh. 1980. Social organization among young beef cattle in confinement. Appl. Anim. Ethol. 6:211-219.

Val-Laillet, D., D. M. Veira, and M. A. G. von Keyserlingk. 2008 Short communication: Dominance in free-stall-housed dairy cattle is dependent upon resource. J. Dairy Sci. 91:3922-3926.

von Keyserlingk, M. A. G., D. Olenick, and D. M. Weary. 2008. Acute behavioral effects of regrouping dairy cows. J. Dairy Sci. 91:10111016.

Welch, J. G. 1982. Rumination, particle size and passage from the rumen. J. Anim. Sci. 54:885-894.

Welp, T., J. Rushen, D. L. Kramer, M. Festa-Bianchet, and A. M. B. de Passillé. 2004. Vigilance as a measure of fear in dairy cattle. Appl. Anim. Behav. Sci. 87:1-13. 